\title{
Using HSV-Thymidine Kinase for Safety in an Allogeneic Salivary Graft Cell Line*
}

\author{
DORON J. AFRAMIAN, D.M.D., M.Sc., ${ }^{1}$ CHANGYU ZHENG, M.D., Ph.D., \\ CORINNE M. GOLDSMITH, B.S., ${ }^{1}$ JANETA NIKOLOVSKI, M.S., ${ }^{2}$ \\ EDNA CUKIERMAN, Ph.D., ${ }^{3}$ KENNETH M. YAMADA, M.D., Ph.D., 3 \\ DAVID J. MOONEY, Ph.D., ${ }^{2}$ HENNING BIRKEDAL-HANSEN, D.D.S., Ph.D., ${ }^{4}$ \\ and BRUCE J. BAUM, D.M.D., Ph.D. ${ }^{1}$
}

\begin{abstract}
Extreme salivary hypofunction is a result of tissue damage caused by irradiation therapy for cancer in the head and neck region. Unfortunately, there is no currently satisfactory treatment for this condition that affects up to 40,000 people in the United States every year. As a novel approach to managing this problem, we are attempting to develop an orally implantable, fluid-secreting device (an artificial salivary gland). We are using the well-studied HSG salivary cell line as a potential allogeneic graft cell for this device. One drawback of using a cell line is the potential for malignant transformation. If such an untoward response occurred, the device could be removed. However, in the event that any HSG cells escaped, we wished to provide additional patient protection. Accordingly, we have engineered HSG cells with a hybrid adeno-retroviral vector, AdLTR.CMV-tk, to express the herpes simplex virus thymidine kinase (HSV-tk) suicide gene as a novel safety factor. Cells were grown on plastic plates or on poly-L-lactic acid disks and then transduced with different multiplicities of infection (MOIs) of the hybrid vector. Thereafter, various concentrations of ganciclovir (GCV) were added, and cell viability was tested. Transduced HSG cells expressed HSV-tk and were sensitive to GCV treatment. Maximal effects were seen at a MOI of 10 with 50 $\mu M$ of GCV, achieving $95 \%$ cell killing on the poly-L-lactic acid substrate. These results suggest that engineering the expression of a suicide gene in an allogeneic graft cell may provide additional safety for use in an artificial salivary gland device.
\end{abstract}

\footnotetext{
${ }^{1}$ Gene Therapy and Therapeutics Branch, National Institute of Dental and Craniofacial Research, National Institutes of Health, Bethesda, Maryland.

${ }^{2}$ Department of Biomedical Engineering, University of Michigan, Ann Arbor, Michigan.

${ }^{3}$ Craniofacial Developmental Biology and Regeneration Branch, National Institute of Dental and Craniofacial Research, National Institutes of Health, Bethesda, Maryland.

${ }^{4}$ Matrix Metalloproteinase Unit, National Institute of Dental and Craniofacial Research, National Institutes of Health, Bethesda, Maryland.

*This work was presented in part at the 78th General Session of the International Association for Dental Research, April 5-8, 2000, Washington, DC.
} 


\section{INTRODUCTION}

A PPROXimately 40,000 new cases of head and neck cancer occur each year in the United States, with about 500,000 new cases worldwide. ${ }^{1}$ In industrialized countries, the vast majority of these patients receive irradiation treatment. The salivary glands are often included in the radiation field. If the irradiation treatment exceeds $\sim 50 \mathrm{~Gy}$, generally irreversible damage occurs to the salivary glands. ${ }^{2}$ Indeed, it has been suggested (for the parotid gland) that a mean dose of $\leq 26$ Gy should be a planning goal if substantial sparing of gland function is desired. ${ }^{3}$ Irradiation results primarily in the destruction of the fluid secreting acinar cells, and in many individuals all salivary epithelial cells are replaced by nonsecretory tissue. ${ }^{4}$ There is no effective conventional therapy for this condition.

We have initiated a project using tissue engineering principles to develop an orally implantable fluid secretory device for such patients. ${ }^{5}$ This device will consist of a blind end tube fabricated from a biodegradable polymer, coated with a suitable extracellular matrix protein, and lined on its lumen by a monolayer of epithelial cells capable of unidirectional fluid transport. ${ }^{6}$

The use of autologous, amplified epithelial cells for the graft cell monolayer in such a device would be ideal, but the growth of acinar (fluid-secreting) mammalian epithelial cells in vitro has thus far been elusive. For this reason, we have chosen to use an allogeneic graft cell, the HSG cell line, as a model for feasibility studies. ${ }^{5}$ These cells are derived from a human submandibular gland ${ }^{7}$ and have been widely employed in physiological studies in vitro. HSG cells exhibit functionally coupled neurotransmitter receptors, intact $\mathrm{Ca}^{2+}$ signaling systems, and various ion channels and transporters important for fluid secretion. ${ }^{8-11}$ Additionally, HSG cells respond to extracellular matrix signals that can direct morphological and tissuespecific differentiation. ${ }^{12-14}$

We recently showed that HSG cells seeded on poly-L-lactic acid coated with human fibronectin resulted in maximal cell growth and organization as a monolayer with a cobblestone, epithelioid appearance. ${ }^{5}$ However, as a cell line, HSG cells possess unlimited growth potential. Although we recognize that an artificial gland device could be easily removed from patients in the event of any untoward host response, we wished to incorporate an additional level of patient safety to eliminate any residual cells after removal of the implant. For this reason we decided to incorporate a suicide gene into HSG cells. We chose the well-studied herpes simplex virus thymidine kinase (HSV-tk) gene initially for proof-of-concept studies.

The HSV-tk gene, in combination with the prodrug ganciclovir (GCV), has been widely employed in cancer gene therapy. GCV is a nucleoside analog that is converted to a monophosphate form in the cell by HSV-tk and then further phosphorylated by host cellular kinases to the triphosphate form. The latter will block DNA elongation and result in cell death. ${ }^{15}$ We hypothesized that, if in the event that any HSG cells escaped from the artificial gland device, by expressing HSV-tk they could be eliminated through the metabolism of the administered GCV. The present report demonstrates that transduction of HSG cells with a hybrid recombinant adeno-retroviral vector leads to expression of HSV-tk and to sensitivity of these cells to GCV.

\section{MATERIALS AND METHODS}

\section{Recombinant viral vector construction}

We constructed a recombinant hybrid adeno-retroviral vector, capable of genomic integration, similar to one recently reported by us. ${ }^{16}$ Adenoviral vectors are widely used in gene transfer. ${ }^{6}$ These vectors can be produced at high titers, and can infect dividing and nondividing cells with considerable efficiency. However, adenoviral vectors exist in the nucleus in an epichromosomal location, making gene expression unstable in the long term. Adenoviral vectors also elicit a potent host immune response making it impossible to readminister vectors after transgene expression wanes. Retroviral vectors, such as those based on the Moloney murine leukemia virus, are able to integrate into the genome, albeit in dividing cells. Unfortunately, these vectors cannot be produced at high titers and have a low gene transfer efficiency. The hybrid adeno-retroviral vector combines the high titer and versatility of adenoviral vectors with the long term expression and genomic integration of retroviral vectors. ${ }^{16}$ 
We removed $2.7 \mathrm{~kb}$ of the $5^{\prime}$ long terminal repeat (LTR), which includes part of the envelope gene [1.5 $\mathrm{kb}$ ], the $5^{\prime}$ LTR $\left[0.57 \mathrm{~kb}\right.$ ], and the packaging sequence [0.63 kb], and $1 \mathrm{~kb}$ of the $3^{\prime}$ LTR (which contains about $0.5 \mathrm{~kb}$ of the envelope gene and the intact $3^{\prime} \mathrm{LTR}$ ) of the Moloney murine leukemia virus from the plasmid pXT1 (Stratagene, La Jolla, CA) by digestion with EcoRI. ${ }^{17}$ SalI linkers were added to both ends of the 5'LTR fragment, and the 3'LTR fragment was filled in to form blunt ends. These two fragments were ligated into pACCMV-pLpA (a generous gift of Dr. C. Newgard, University of Texas-Southwestern) from which the CMV promoter/enhancer and the SV40 polyadenylation sequence had been deleted. Thereafter, the CMV promoter/enhancer and the SV40 polyadenylation sequence were reinserted between the $5^{\prime}$ and 3'LTRs using BglII and BamHI sites. This created the plasmid pAC5'3'LTR.CMV. A unique BamHI site remained that could be used to insert the gene of interest. This plasmid was linearized by BamHI digestion and treated with Klenow fragment to form blunt ends. The $1149 \mathrm{bp}$ HSV-tk cDNA was excised from the plasmid pbTK (a generous gift of Dr. F. Candotti, NHGRI, NIH) by BamHI and EcoRI, and filled in with Klenow fragment to form blunt ends. The excised HSV-tk cDNA was then cloned into pAC5'3'LTR.CMV to create the plasmid pAC5'3'LTR.CMV-tk. Restriction analysis and DNA sequencing verified the plasmid construction. Next, pAC5'3'LTR.CMV-tk was cotransfected into 293 cells with the adenoviral (type 5; $\mathrm{E}^{-}, \mathrm{E}^{-}{ }^{-}$) plasmid pBHG10 to create a replication-deficient recombinant adenoretroviral vector by homologous recombination. ${ }^{16,18}$ This hybrid vector, AdLTR.CMV-tk, contains the Moloney murine leukemia virus 5' and 3'LTRs, and the HSV-tk cDNA with the CMV promoter/enhancer and SV40 polyadenylation sequence (Fig. 1).

\section{Cells and cell culture}

HSG cells were a generous gift from Prof. M. Sato (Tokushima University, Japan) ${ }^{7}$ and were maintained in vitro as previously described. ${ }^{19}$ For the experiments presented herein, HSG cells were dispersed from semiconfluent plates using a solution of Versene 1:5000 in Hanks' balanced salt solution without calcium and magnesium (BioFluids, Rockville MD). Cells were then resuspended in fresh media consisting of a 1:1
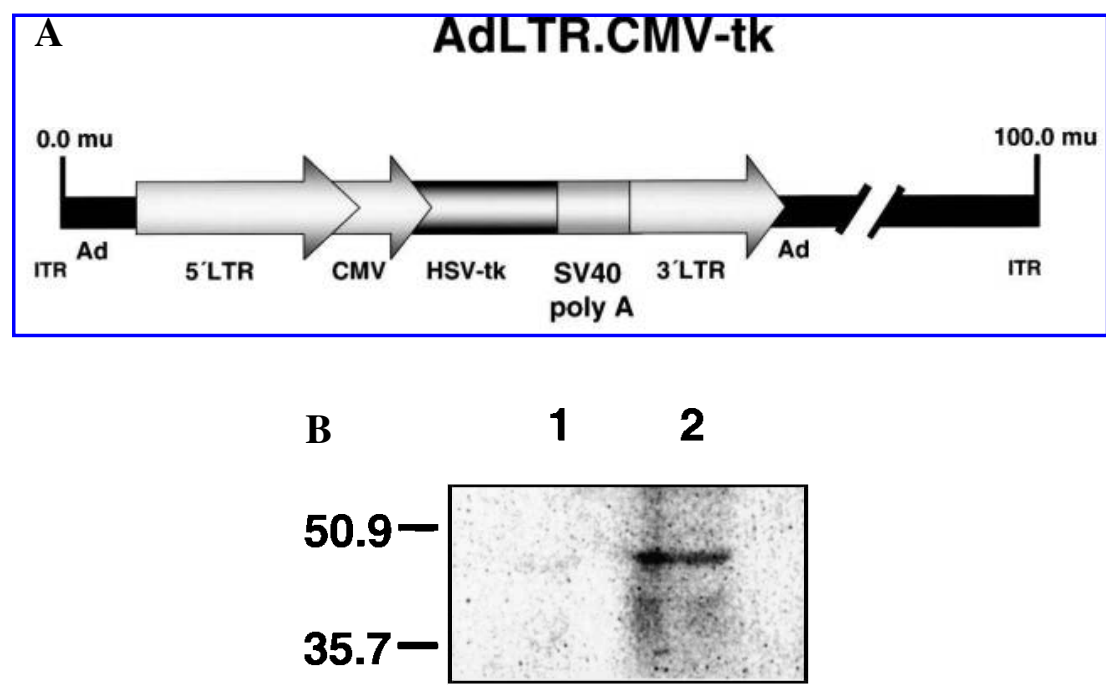

FIG. 1. (A) Schematic illustration of the hybrid adeno-retrovirus vector, AdLTR.CMV-tk. Shown are the Moloney murine leukemia virus $5^{\prime}$ and $3^{\prime}$ long terminal repeats (LTRs; $2.7 \mathrm{~kb}$ and $1 \mathrm{~kb}$, respectively), the CMV promoter/enhancer, the SV40 polyadenylation sequence (poly A), and the HSV-tk cDNA (1149 bp). Adenoviral (Ad) sequences are shown as black bars. ITR, inverted terminal repeat. (B) Western blot analysis of HSG cell extracts. HSG cells were infected or not with AdLTR.CMV-tk at a MOI of 30 in 150-mm plates. After $72 \mathrm{~h}$, cells from noninfected and infected cultures (lanes 1 and 2, respectively) were lysed, and $25 \mu \mathrm{g}$ of total protein were electrophoresed, blotted onto nitrocellulose membranes, and incubated with mouse monoclonal antibody $10 \mathrm{C} 11$ anti-HSV-tk. Molecular mass markers are shown (in $\mathrm{kDa})$. 
mixture of Eagle's minimal essential medium (Dulbecco's modification) and Ham's F-12 supplemented with $2 \mathrm{mM}$ glutamine (BioFluids), 10\% fetal calf serum (Hyclone, Logan, UT), and 100 units/mL penicillin, $100 \mu \mathrm{g} / \mathrm{mL}$ streptomycin, and $2.5 \mu \mathrm{g} / \mathrm{mL}$ fungizone (BioFluids).

\section{Infection and ganciclovir application}

Cells were grown in 96-well culture plates at a density of $1 \times 10^{4}$ cells/well. After $24 \mathrm{~h}$, cells were infected with AdLTR.CMV-tk at different MOIs (defined as plaque-forming units per cell). Six hours after infection, GCV (Cytovene ${ }^{\circledR}$, Syntex Laboratories, Inc., Palo Alto, CA) was added to the media at concentrations of $0.5,5$, or $50 \mu \mathrm{M}$. After incubation for different time points, the sensitivity of cells to the GCV prodrug was evaluated using two separate methods, assaying either with the tetrazolium salt of 3-(4,5-dimethylthiazol-2-yl)-2,5-diphenyl tetrasodium bromide (MTT assay, Chemicon International Inc., Temecula, CA) or direct cell counting after trypan blue staining (Bio-Whittaker, Walkersville, MD).

\section{Polymer disk preparation}

Two-dimensional films of poly-L-lactic acid (Boehringer Ingelheim Inc., Winchester, VA) were produced by melt processing polymer pellets between sheets of aluminum foil using a Carver press at $350^{\circ} \mathrm{F}$ to create disks with diameters of $20-25 \mathrm{~mm}$. The disks were sterilized using $\gamma$-irradiation for $\sim 150$ min with a dose of 20,000 Gy.

\section{Cell growth on polymer disks}

Disks were gently placed in each well of a six-well tissue culture plate (Becton Dickinson, Franklin Lakes, $\mathrm{NJ}$ ) and immersed in phosphate-buffered saline (PBS; GibcoBRL, Grand Island, NY) for $18 \mathrm{~h}$ with $5 \mu \mathrm{g} / \mathrm{mL}$ fibronectin at $37^{\circ} \mathrm{C} .5^{5}$ Thereafter, the coated disks were blocked for $1 \mathrm{~h}$ with bovine serum albumin (Calbiochem-Novabiochem Corp., La Jolla, CA) at $37^{\circ} \mathrm{C}$ and then gently washed twice with PBS. ${ }^{5}$ Cell suspensions $\left(2 \times 10^{5}\right.$ cells; $2 \mathrm{~mL} /$ well $)$ were added in complete culture medium and incubated at $37^{\circ} \mathrm{C}$ for an additional $18 \mathrm{~h}$. Thereafter, the medium was discarded, and $10 \mathrm{MOI}$ of virus diluted in PBS was added for an additional 6 h. Next, GCV diluted in medium was added, and after an additional $125 \mathrm{~h}$, the disks were washed twice in PBS, then stained with $0.2 \%$ crystal violet in $20 \%$ ethanol for $20 \mathrm{~min}^{5}$ The disks were then rinsed twice with PBS and examined under a light microscope using a $\times 10$ objective. Three randomly selected photomicrographs were obtained from each specimen using 200 ASA color slide film (Elite Chrome, Kodak, Rochester, NY). The slides were scanned to convert them to digital images and, using Adobe Photoshop ${ }^{\circledR}$, three $200 \mu \mathrm{m}^{2}$ regions were randomly chosen from each field, and cell number was determined visually.

\section{Western blot analysis of thymidine kinase}

Infected and noninfected HSG cells were grown for $72 \mathrm{~h}$ in $150-\mathrm{mm}$ tissue culture plates. Thereafter, cells were scraped from the plates and hypotonically lysed with $1 \mathrm{mM} \mathrm{NaHCO}_{3}$ and $1 \mathrm{mM}$ 4-(2-aminoethyl)benzenesulfonyl fluoride hydrochloride, a serine protease inhibitor (ICN Biomedicals Inc., Aurora, OH). The cell lysate was frozen, thawed and vortexed for three cycles, and then centrifuged at 1,000g for $20 \mathrm{~min}$. The resulting supernatant was precipitated with $80 \%$ ethanol for $17 \mathrm{~h}$ at $-20^{\circ} \mathrm{C}$ and centrifuged at $16,000 \mathrm{~g}$ for $20 \mathrm{~min}$. The resulting pellet was solublized in double-distilled water, and the protein concentration was determined by the Bio-Rad/Bradford dye-binding protein assay (Bio-Rad Laboratories, Hercules, CA). Next, samples were mixed with an equal volume of $2 \times$ sample loading buffer and heated at $95^{\circ} \mathrm{C}$ for 5 min before loading $25 \mu \mathrm{g}$ of total protein on a polyacrylamide gel. The samples were resolved by electrophoresis using $12 \%$ Tris- $\mathrm{HCl}$ precast polyacrylamide gels (Bio-Rad), and the proteins were transferred onto nitrocellulose membranes. Membranes were incubated in 5\% nonfat dry milk in supplemented TBS-T (Geno Technology, St. Louis, MO; Tris-buffered saline-Tween stock with additional $0.1 \%$ Tween 20 ), plus $1 \%$ bovine serum albumin, for $1 \mathrm{~h}$. Thereafter, the membrane was incubated with a 1:250 dilution of mouse monoclonal antibody 10C11 anti-HSV-tk (obtained from Dr. W. Summers, Yale University) for $1 \mathrm{~h}$ at room temperature. The membrane was transferred to a solution containing a 1:500 dilution of anti-mouse-IgG 
horseradish peroxidase-conjugated antibody solution in TBS-T (Amersham Life Science Inc., Arlington Heights, IL), and the incubation was continued for $1 \mathrm{~h}$. Between each step, the membrane was washed twice for $7 \mathrm{~min}$ each in fresh supplemented TBS-T and then washed once with TBS-T stock alone. Finally, the membrane was incubated for $3 \mathrm{~min}$ in femtoLUCENT Western detection reagent (Geno Technology) and exposed to X-OMAT film (Kodak).

\section{Statistics}

Mean values \pm SEM for various groups were compared using a two-way analysis of variance with a $95 \%$ confidence interval.

\section{RESULTS}

\section{Thymidine kinase production by infected HSG cells}

In order to verify the production of the HSV-tk protein, HSG cells were infected with AdLTR.CMV-tk at a MOI of 30 for $72 \mathrm{~h}$. No cytopathic effects were seen in the infected cells. Western blot analysis of cell extracts clearly showed a single, approximately 40-kDa immunoreactive protein band in samples from the infected cells corresponding to the expected molecular weight of the HSV-tk protein ${ }^{20,21}$ (Fig. 1B). This protein band was not detectable in extracts from the control, noninfected cells.

\section{Effects of ganciclovir on HSG cells grown on plastic}

To assess the ability of the HSV-tk transgene to function in HSG cells, we initially studied cell viability on tissue culture plastic using the MTT assay. HSG cells were infected with different vector MOIs, and thereafter incubated with several concentrations of GCV previously shown to be useful. ${ }^{22}$ In the absence of GCV, HSG cells infected with AdLTR.CMV-tk at a MOI of either 1 or 10 grew normally (Fig. 2). Cells infected with AdLTR.CMV-tk at a MOI of 100, however, exhibited substantially decreased viability even without GCV exposure. GCV was without effect on uninfected cells or on cells infected with AdLTR.CMVtk at a MOI of 1 . However, cells infected at a MOI of 10 were sensitive to GCV, showing $>50 \%$ reduced viability at all prodrug concentrations used $(p<0.02,0.006$, and 0.004 for $0.5,5$, and $50 \mu \mathrm{M}$ of GCV, respectively) compared to no GCV treatment.

To determine the surviving cell number under these growth conditions on a plastic substrate following GCV treatment, in separate experiments we used trypan blue staining and manual cell counting (Fig. 3). These results were consistent with the observations shown in Figure 2. Administration of GCV to cells infected with AdLTR.CMV-tk at a MOI of 10 demonstrated a substantial decrease (up to threefold) in number of viable cells compared with cells infected with $10 \mathrm{MOI}$ alone $(p<0.02,0.0004$, and 0.001 for 0.5 ,

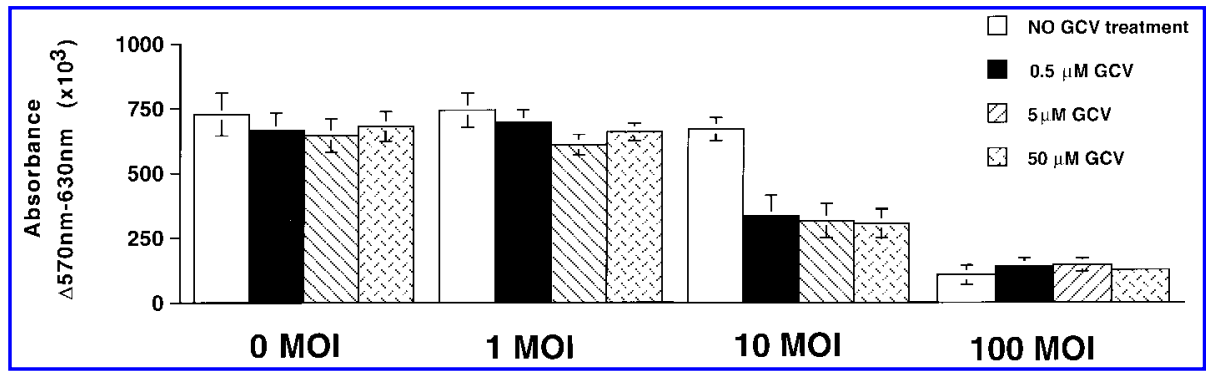

FIG. 2. Effect of ganciclovir on cell viability with the MTT assay. HSG $\left(1 \times 10^{4}\right)$ cells were plated in 96 -well plates and, after $18 \mathrm{~h}$, infected with AdLTR.CMV-tk at a MOI of 1, 10, or 100. After an additional 6 h, media were discarded and ganciclovir (GCV) diluted in media was added at the concentrations indicated. After 144 h, cell viability was determined using the MTT assay. Data shown are the mean \pm SEM for seven individual determinations from two separate experiments. 


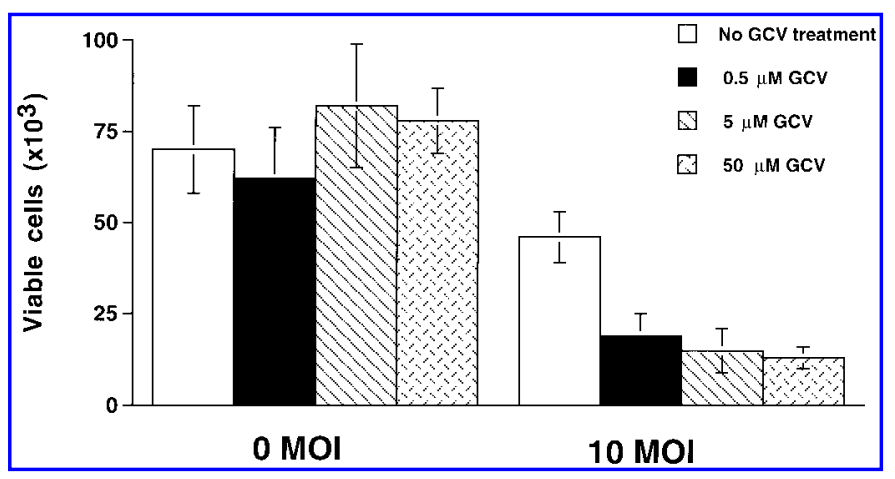

FIG. 3. Effect of ganciclovir on the number of viable cells on tissue culture plastic. HSG $\left(1 \times 10^{4}\right)$ cells were plated in 96-well plates and infected with AdLTR.CMV-tk at a MOI of 10. After an additional $6 \mathrm{~h}$, media were discarded, and ganciclovir (GCV) diluted in media was added at the concentrations indicated. After $144 \mathrm{~h}$, the numbers of viable cells were counted visually using trypan blue. Data shown are the mean \pm SEM for eight individual determinations from two separate experiments.

5 , and $50 \mu \mathrm{M} \mathrm{GCV}$, respectively). In this set of experiments, note that a modest but significant reduction in cell viability was observed in cells infected with virus at a MOI of 10 in the absence of GCV $(p<0.03)$.

\section{Effect of ganciclovir on HSG cells grown on poly-L-lactic acid disks}

The envisioned artificial salivary gland device will have cells grown as a monolayer on a fibronectincoated poly-L-lactic acid substratum, ${ }^{5}$ rather than on tissue culture plastic. Therefore, we determined the ability of GCV to elicit HSG cell death when attached to poly-L-lactic acid disks precoated with $5 \mu \mathrm{g} / \mathrm{mL}$ of human fibronectin. As shown in Figure 4A, cells infected with AdLTR.CMV-tk (MOI of 10) were quite sensitive to exposure to GCV in a concentration-dependent manner. The GCV effect ranged from $40 \%$ cell death at $0.5 \mu \mathrm{M} \mathrm{GCV}$ to $95 \%$ cell death when the GCV concentration was $50 \mu \mathrm{M}$ (Fig. 4A). HSG cells treated with $50 \mu \mathrm{M}$ GCV alone appeared normal with a typical epithelioid cobblestone appearance of cell monolayers (Fig. 4B). Infection of cells with AdLTR.CMV-tk at a MOI of 10, followed by treatment with $50 \mu \mathrm{M}$ of GCV, resulted in the loss of almost all of the cells from the disk (Fig. 4B).

\section{DISCUSSION}

The purpose of this study was to test the susceptibility to GCV of HSG cells engineered to express the HSV-tk suicide gene. We envision that inclusion of such a suicide gene could serve to provide added safety for future in vivo applications of HSG cells in an artificial salivary gland device. This study is part of our effort to develop an orally implantable fluid secretory device for patients suffering from irreversible damage to their salivary glands after irradiation. As noted above, the prototype design of such a device includes a blind-end tube made out of a biodegradable polymer as a scaffold, coated with matrix proteins, and lined on its lumen with a monolayer of graft cells. ${ }^{6}$ This device would be implanted in the buccal mucosal tissue with an exit to the oral cavity, mimicking the orifices of the natural salivary duct system. ${ }^{6}$

For initial feasibility studies, we have chosen to use HSG cells because they possess many of the physiological signaling and transport features necessary for fluid secretion. ${ }^{8-11}$ However, as a cell line, a significant drawback to their use is their transformation potential. We reasoned that the HSV-tk, or another, suicide gene may provide some protection against this drawback, well beyond that achieved merely by removal of the device. In cells expressing HSV-tk, the prodrug GCV is phosphorylated to its triphosphate metabolite. This derivative then competes with endogenous dGTP pools for incorporation into DNA and subsequently results in premature chain termination. ${ }^{15}$ Thus, in the event of an untoward host response to cells, GCV can be administered and converted by the expressed HSV-tk to the cytotoxic triphosphate form 

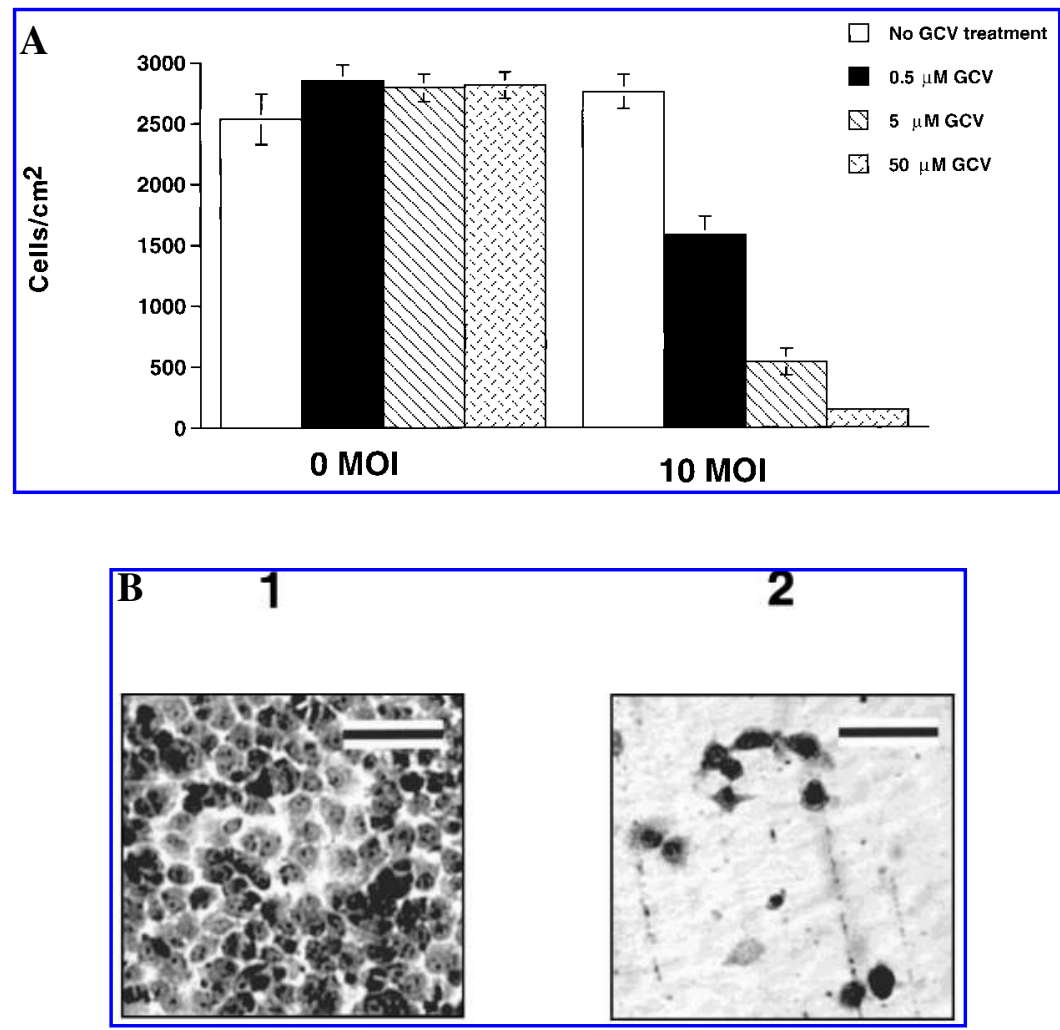

FIG. 4. (A) Effect of ganciclovir on HSG cells grown on poly-L-lactic acid disks. HSG cells $\left(2 \times 10^{5} /\right.$ well $)$ were plated on poly-L-lactic acid coated with human fibronectin. Thereafter, media were discarded, and AdLTR.CMV-tk, at a MOI of 10 diluted in PBS, was added. After $6 \mathrm{~h}$, ganciclovir (GCV) was added in different concentrations to the media as indicated. After an additional $125 \mathrm{~h}$, the disks were stained with $0.2 \%$ crystal violet in $20 \%$ ethanol; three randomly selected photomicrographs were obtained from each; and the number of attached cells was determined visually. The data shown are the mean \pm SEM for 18 individual determinations from two separate experiments. All results with GCV treatment of infected cells were significantly different from control cells $(p<0.0001)$. (B) Appearance of HSG cells with or without infection by AdLTR.CMV-tk after GCV treatment. A selected $200 \mu \mathrm{m}^{2}$ region from representative cell cultures on poly-L-lactic acid is shown. Photomicrograph 1 represents HSG cells treated with $50 \mu \mathrm{M}$ GCV alone. Photomicrograph 2 represents HSG cells infected with AdLTR-tk at a MOI of 10, in addition to exposure to 50 $\mu \mathrm{M}$ GCV. Bar $=50 \mu \mathrm{m}$.

leading to cell death, and thus host protection. This cytotoxicity is enhanced by a bystander effect in which cell death results from the phosphorylated GCV entering adjacent cells via gap junctions. ${ }^{23}$

We delivered the HSV-tk gene to HSG cells via a replication-deficient recombinant adeno-retroviral vector, AdLTR.CMV-tk. As we recently reported, the prototype for this hybrid vector is able to direct random genomic integration of the transgene and long-term gene expression into both dividing and nondividing cells in vitro and in vivo. ${ }^{16}$ AdLTR.CMV-tk infection was without effect on HSG cell growth and viability at MOIs of $\leq 10$ (Figs. 2 and 3). This is consistent with earlier reports showing maintenance of the functional integrity of HSG cells after infection with low doses of type 5 adenoviral vectors in vitro. ${ }^{24,25}$ The encoded suicide gene is expressed in HSG cells, but it is essentially functionally latent until GCV administration. GCV, at doses up to $50 \mu \mathrm{M}$, is without effect on HSG cell growth and viability in the absence of AdLTR.CMV-tk infection (Figs. 2 and 3). However, we demonstrated that HSG cells expressing thymidine kinase after AdLTR.CMV-tk infection are quite sensitive to GCV, with cell viability reduced as much as $95 \%$.

The HSV-tk suicide gene/GCV system was first described by Culver et al. for the treatment of experimental brain tumors. ${ }^{26}$ Subsequently, this system has been widely used as a strategy for treating cancers in a variety of other tissues. ${ }^{27-30} \mathrm{HSV}$-tk gene transfer has also been applied to prevent posterior capsule opaci- 
fication after cataract surgery ${ }^{31}$ and as a tool to reduce graft-versus-host disease. ${ }^{32}$ Recently, during the course of this study, a report appeared using the HSV-tk gene to decrease the risk of immortalized human hepatocytes as mismatched allografts in life-saving metabolic support during acute liver failure. ${ }^{33}$ To our knowledge, the present study is the first attempt to utilize the HSV-tk gene for safety with allogeneic graft cells for a bioartificial organ. Suicide gene technology may be a valuable way to circumvent certain problems associated with allografts or xenografts. ${ }^{34}$

In conclusion, this study shows that, after infection with a hybrid recombinant adeno-retrovirus capable of long-term expression and encoding HSV-tk, HSG cells are efficiently killed by GCV treatment. This suggests that the AdLTR.CMV-tk vector may be useful to provide an additional measure of safety for the use of allogeneic graft cells in an artificial tissue device.

\section{REFERENCES}

1. Vokes, E.E., Weichselbaum, R.R., Lippman, S.M., and Hong, W.K. Head and neck cancer. N. Engl. J. Med. 328, 184, 1993.

2. Taylor, S.E., and Miller, E.G. Preemptive pharmacologic intervention in radiation-induced salivary dysfunction. Proc. Soc. Exp. Biol. Med. 221, 14, 1999.

3. Eisbruch, A., Ten Haken, R.K., Kim, H.M., Marsh, L.H., and Ship, J.A. Dose, volume, and function relationships in parotid salivary glands following conformal and intensity-modulated irradiation of head and neck cancer. Int. J. Radiat. Oncol. Biol. Phys. 45, 577, 1999.

4. Kashima, H.K., Kirkham, J.R., and Andrews, J.R. Postirradiation sialadenitis. A study of the clinical features, histopathologic changes and serum enzyme variations following irradiation of human salivary glands. Am. J. Roentgenol. Radium Ther. Nucl. Med. 94, 77, 1965.

5. Aframian, D.J., Cukierman, E., Nikolovski, J., Mooney, D.J., Yamada, K.M., and Baum, B.J. The growth and morphological behavior of salivary epithelial cells on matrix protein-coated biodegradable substrata. Tissue Eng. 6, 209, 2000.

6. Baum, B.J., Wang, S., Cukierman, E., Delporte, C., Kagami, H., Marmary, Y., Fox, P.C., Mooney, D.J., and Yamada, K.M. Re-engineering the functions of a terminally differentiated epithelial cell in vivo. Ann. N.Y. Acad Sci. 875, 294, 1999.

7. Shirasuna, K., Sato, M., and Miyazaki, T. A neoplastic epithelial duct cell line established from an irradiated human salivary gland. Cancer 48, 745, 1981.

8. Ship, J.A., Patton, L.L., and Wellner, R.B. Muscarinic regulation of potassium transport in a human submandibular epithelial cell line. Am. J. Physiol. 259, C340, 1990.

9. Kaplan, M.D., Taylor, S.E., Ambudkar, I.S. G-protein- and capacitatively regulated $\mathrm{Ca}^{2+}$ entry pathways are activated by muscarinic receptor stimulation in a human submandibular ductal cell line. Pflugers Arch. 428, 439, 1994.

10. Liu, X., O'Connell, A., and Ambudkar, I.S. $\mathrm{Ca}^{2+}$-dependent inactivation of a store-operated $\mathrm{Ca}^{2+}$ current in human submandibular gland cells. Role of a staurosporine-sensitive protein kinase and the intracellular $\mathrm{Ca}^{2+}$ pump. J. Biol. Chem. 273, 33295, 1998.

11. Izutsu, K.T., Fatherazi, S., Wellner, R.B., Herrington, J., Belton, C.M., and Oda, D. Characteristics and regulation of a muscarinically activated K current in HSG-PA cells. Am. J. Physiol. 266, C58, 1994.

12. Royce, L.S., Kibbey, M.C., Mertz, P., Kleinman, H.K., and Baum, B.J. Human neoplastic submandibular intercalated duct cells express an acinar phenotype when cultured on a basement membrane matrix. Differentiation $\mathbf{5 2}$, 247, 1993.

13. Hoffman, M.P., Nomizu, M., Roque, E., Lee, S., Jung, D.W., Yamada, Y., and Kleinman, H.K. Laminin-1 and laminin-2 G-domain synthetic peptides bind syndecan-1 and are involved in acinar formation of a human submandibular gland cell line. J. Biol. Chem. 273, 28633, 1998.

14. Lafrenie, R.M., and Yamada, K.M. Integrins and matrix molecules in salivary gland cell adhesion, signaling, and gene expression. Ann. N.Y. Acad. Sci 842, 42, 1998.

15. Boucher, P.D., Ruch, R.J., and Shewach, D.S. Differential ganciclovir-mediated cytotoxicity and bystander killing

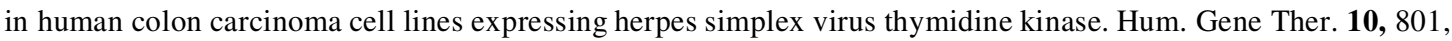
1998.

16. Zheng, C., Baum, B.J., Iadarola, M.J., and O'Connell, B.C. Genomic integration and gene expression by a modified adenoviral vector. Nat. Biotechnol. 18, 176, 2000. 


\section{HSV-tk IN SALIVARY ALLOGENEIC GRAFT CELLS}

17. Boulter, C.A., and Wagner, E.F. A universal retroviral vector for efficient constitutive expression of exogenous genes. Nucleic Acids Res. 15, 7194, 1987.

18. Becker, T.C., Noel, R.J., Coats, W.S., and Newgard, C. Use of recombinant adenovirus for metabolic engineering of mammalian cells. Methods Cell Biol. 43, 161, 1994.

19. He, X.J., Wu, X.Z., and Baum, B.J. The effect of $N$-(6-aminohexyl)-5-chloro-1-naphthalenesulfonamide (W-7) on muscarinic receptor-induced $\mathrm{Ca}^{2+}$ mobilization in a human salivary epithelial cell line. Pflugers Arch. 36, 416, 1990.

20. Kit, S., Jorgensen, G.N., Dubbs, D.R., Trkula, D., and Zaslavsky, V. Detection of herpes simplex virus thymidine kinase polypeptides in cells labeled with ${ }^{35}$ S-methionine. Intervirology $9,162,1990$.

21. Uckert, W., Kammertons, T., Haack, K., Qin, Z., Gebert, J., Schendel, D.J., and Blankenstein, T. Double suicide gene (cytosine deaminase and herpes simplex virus thymidine kinase) but not single gene transfer allows reliable elimination of tumor cells in vivo. Hum. Gene Ther. 10, 855, 1998.

22. Candotti, F., Agbaria, R., Mullen, C.A., Touraine, R., Balzarini, J., Johns, D.G., and Blaese, R.M. Use of a herpes thymidine kinase/neomycin phosphotransferase chimeric gene for metabolic suicide gene transfer. Cancer Gene Ther. 7, 574, 2000.

23. Dilber, M.S., Abedi, M.R., Christensson, B., Bjorkstrand, B., Kidder, G.M., Naus, C.C., Gahrton, G., and Smith, C.I. Gap junctions promote the bystander effect of herpes simplex virus thymidine kinase in vivo. Cancer Res. 57, $1523,1997$.

24. Zheng, C., Hoffman, M.P., McMillan, T., Kleinman, H.K., and O'Connell, B.C. Growth factor regulation of the amylase promoter in a differentiating salivary acinar cell line. J. Cell. Physiol. 177, 628, 1998.

25. Zheng, C., Goldsmith, C.M., O'Connell, B.C., and Baum, B.J. Adenoviral vector cytotoxicity depends in part on the transgene encoded. Biochem. Biophys. Res. Commun. 274, 767, 2000.

26. Culver, K.W., Ram, Z., Wallbridge, S., Ishii, H., Oldfield, E.H., and Blaese, R.M. In vivo gene transfer with retroviral vector-producer cells for treatment of experimental brain tumors. Science 256, 1550, 1992.

27. Shalev, M., Miles, B.J., Thompson, T.C., Ayala, G., Butler, E.B., Aguilar-Cordova, E., and Kadmon, D. Suicide gene therapy for prostate cancer using a replication-deficient adenovirus containing the herpesvirus thymidine kinase gene. World J. Urol. 18, 125, 2000.

28. Wildner, O., Blaese, R.M., and Morris, J.C. Therapy of colon cancer with oncolytic adenovirus is enhanced by the addition of herpes simplex virus-thymidine kinase. Cancer Res. 59, 410, 1999.

29. Matsubara, H., Kawamura, K., Sugaya, M., Koide, Y., Gunji, Y., Takenaga, K., Asano, T., Ochiai, T., Sakiyama, S., and Tagawa, M. Differential efficacy of suicide gene therapy by herpes simplex virus-thymidine kinase gene reflects the status of p53 gene in human esophageal cancer cells. Anticancer Res. 19, 4157, 1999.

30. Anderson, L.M., Swaminathan, S., Zackon, I., Tajuddin, A.K., Thimmapaya, B., and Weitzman, S.A. Adenovirusmediated tissue-targeted expression of the HSVtk gene for the treatment of breast cancer. Gene Ther. 6, 854, 1999.

31. Malecaze, F., Couderc, B., de Neuville, S., Serres, B., Mallat, J., Douin-Echinard, V., Manenti, S., Revah, F., and Darbon, J.M. Adenovirus-mediated suicide gene transduction: feasibility in lens epithelium and in prevention of posterior capsule opacification in rabbits. Hum. Gene Ther. 10, 2365, 1999.

32. Verzeletti, S., Bonini, C., Marktel, S., Nobili, N., Ciceri, F., Traversari, C., and Bordignon, C. Herpes simplex virus thymidine kinase gene transfer for controlled graft-versus-host disease and graft-versus-leukemia: clinical followup and improved new vectors. Hum. Gene Ther. 9, 2243, 1998.

33. Kobayashi, N., Fujiwara, T., Westerman, K.A., Inoue, Y., Sakaguchi, M., Noguchi, H., Miyazaki, M., Cai, J., Tanaka, N., Fox, I.J., and Leboulch, P. Prevention of acute liver failure in rats with reversibly immortalized human hepatocytes. Science 287, 258, 2000.

34. McKay, R. Stem cells-hype and hope. Nature 406, 361, 2000.

Address reprint requests to:

Bruce J. Baum, D.M.D., Ph.D.

GTTB, NIDCR, NIH

Bldg. 10, Rm $1 N 113$

MSC-1190

Bethesda, MD 20892

E-mail: bbaum@dir.nidcr.nih.gov 


\section{This article has been cited by:}

1. Doron J. Aframian , Aaron Palmon . 2008. Current Status of the Development of an Artificial Salivary GlandCurrent Status of the Development of an Artificial Salivary Gland. Tissue Engineering Part B: Reviews 14:2, 187-198. [Abstract] [PDF] [PDF Plus]

2. Doron J. Aframian, Doron Amit , Ran David, Ela Shai , Dan Deutsch, Alexander Honigman , Amos Panet, Aaron Palmon . 2007. Reengineering Salivary Gland Cells to Enhance Protein Secretion for Use in Developing Artificial Salivary Gland DeviceReengineering Salivary Gland Cells to Enhance Protein Secretion for Use in Developing Artificial Salivary Gland Device. Tissue Engineering 13:5, 995-1001. [Abstract] [PDF] [PDF Plus]

3. Bruce J. Baum, Simon D. Tran. 2006. Synergy between genetic and tissue engineering: creating an artificial salivary gland. Periodontology 2000 41:1, 218-223. [CrossRef]

4. S.D. Tran , J. Wang, B.C. Bandyopadhyay, R.S. Redman , A. Dutra, E. Pak, W.D. Swaim, J.A. Gerstenhaber, J.M. Bryant, C. Zheng, C.M. Goldsmith , M.R. Kok , R.B. Wellner , B.J. Baum . 2005. Primary Culture of Polarized Human Salivary Epithelial Cells for Use in Developing an Artificial Salivary GlandPrimary Culture of Polarized Human Salivary Epithelial Cells for Use in Developing an Artificial Salivary Gland. Tissue Engineering 11:1-2, 172-181. [Abstract] [PDF] [PDF Plus]

5. D.J. Aframian , R. David , H. Ben-Bassat , E. Shai , D. Deutsch , B.J. Baum , A. Palmon . 2004. Characterization of Murine Autologous Salivary Gland Graft Cells: A Model for Use with an Artificial Salivary GlandCharacterization of Murine Autologous Salivary Gland Graft Cells: A Model for Use with an Artificial Salivary Gland. Tissue Engineering 10:5-6, 914-920. [Abstract] [PDF] [PDF Plus]

6. Giuseppe Intini , Sebastiano Andreana , Joseph E. Margarone III , Peter J. Bush , Rosemary Dziak . 2002. Engineering a Bioactive Matrix by Modifications of Calcium SulfateEngineering a Bioactive Matrix by Modifications of Calcium Sulfate. Tissue Engineering 8:6, 997-1008. [Abstract] [PDF] [PDF Plus]

7. D.J. Aframian, S.D. Tran , E. Cukierman, K.M. Yamada , B.J. Baum . 2002. Absence of Tight Junction Formation in an Allogeneic Graft Cell Line Used for Developing an Engineered Artificial Salivary GlandAbsence of Tight Junction Formation in an Allogeneic Graft Cell Line Used for Developing an Engineered Artificial Salivary Gland. Tissue Engineering 8:5, 871-878. [Abstract] [PDF] [PDF Plus]

8. D.J. Aframian , R.S. Redman , S. Yamano , J. Nikolovski , E. Cukierman , K.M. Yamada , M.F. Kriete , W.D. Swaim , D.J. Mooney , B.J. Baum . 2002. Tissue Compatibility of Two Biodegradable Tubular Scaffolds Implanted Adjacent to Skin or Buccal Mucosa in MiceTissue Compatibility of Two Biodegradable Tubular Scaffolds Implanted Adjacent to Skin or Buccal Mucosa in Mice. Tissue Engineering 8:4, 649-659. [Abstract] [PDF] [PDF Plus] 